\title{
Thermal Cook-off of an HMX Based Explosive: Pressure Gauge Experiments and Modeling
}

\author{
P. A. Urtiew, J. W. Forbes, C. M. Tarver, F. Garcia, D. W. \\ Greenwood, K. S. Vandersall
}

This article was submitted to

International Workshop: New Models and Hydrocodes for Shock Wave Processes in Condensed Matter, Edinburgh, Scotland, May 19-24, 2002

U.S. Department of Energy

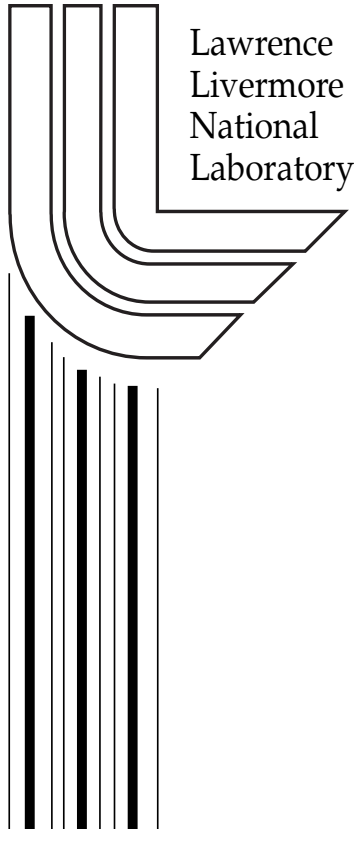

April 2, 2002 


\section{DISCLAIMER}

This document was prepared as an account of work sponsored by an agency of the United States Government. Neither the United States Government nor the University of California nor any of their employees, makes any warranty, express or implied, or assumes any legal liability or responsibility for the accuracy, completeness, or usefulness of any information, apparatus, product, or process disclosed, or represents that its use would not infringe privately owned rights. Reference herein to any specific commercial product, process, or service by trade name, trademark, manufacturer, or otherwise, does not necessarily constitute or imply its endorsement, recommendation, or favoring by the United States Government or the University of California. The views and opinions of authors expressed herein do not necessarily state or reflect those of the United States Government or the University of California, and shall not be used for advertising or product endorsement purposes.

This is a preprint of a paper intended for publication in a journal or proceedings. Since changes may be made before publication, this preprint is made available with the understanding that it will not be cited or reproduced without the permission of the author.

This work was performed under the auspices of the United States Department of Energy by the University of California, Lawrence Livermore National Laboratory under contract No. W-7405-Eng-48.

This report has been reproduced directly from the best available copy.

Available electronically at http://www.doc.gov/bridge

Available for a processing fee to U.S. Department of Energy

And its contractors in paper from

U.S. Department of Energy

Office of Scientific and Technical Information

P.O. Box 62

Oak Ridge, TN 37831-0062

Telephone: (865) 576-8401

Facsimile: (865) 576-5728

E-mail: reports@adonis.osti.gov

Available for the sale to the public from

U.S. Department of Commerce

National Technical Information Service

5285 Port Royal Road

Springfield, VA 22161

Telephone: (800) 553-6847

Facsimile: (703) 605-6900

E-mail: orders@ntis.fedworld.gov

Online ordering: http://www.ntis.gov/ordering.htm

OR

Lawrence Livermore National Laboratory

Technical Information Department's Digital Library

http://www.llnl.gov/tid/Library.html 


\title{
Thermal Cook-off of an HMX Based Explosive: Pressure Gauge Experiments and Modeling.
}

\author{
Paul A. Urtiew, Jerry W. Forbes, Craig M. Tarver, \\ Frank Garcia, Daniel W. Greenwood and Kevin S. Vandersall \\ Lawrence Livermore National Laboratory \\ P.O. Box 808, L-282 \\ Livermore, CA 94551
}

\begin{abstract}
Safety issues related to thermal cook-off are important for handling and storing explosive devices. Violence of event as a function of confinement is important for prediction of collateral events. There are major issues, which require an understanding of the following events: (1) transit to detonation of a pressure wave from a cook-off event, (2) sensitivity of HMX based explosives changes with thermally induced phase transitions and (3) the potential danger of neighboring explosive devices being affected by a cook-off reaction. Results of cook-off events of known size, confinement and thermal history allows for development and/or calibrating computer models for calculating events that are difficult to measure experimentally.
\end{abstract}

\section{INTRODUCTION}

A better understanding of thermal cook-off is important for safe handling and storing explosive devices. Questions exist on the level of violence of these events as a function of confinement and thermal heating rates. In addition, the acceleration of the metal case by this type of thermal reaction is needed to assess whether the resulting flyer can initiate detonation or reaction in a neighboring explosive item. In this paper we will demonstrate how adjacent materials can be gauged to measure the resulting pressure wave and how this wave propagates in an adjacent material. The output pulse from the thermal cook-off explosive containing fixture is of obvious interest for assessing many scenarios.

\section{EXPERIMENTAL PROCEDURES}

Three different experiments have been performed. Two of them contained stainless steel encased PBX 9501 (HMX/Estane/BDNPA-F; 95/2.5/2.5 wt \%) donor charges, which were allowed to thermally explode. A transmitted two-dimensional pressure wave was measured by gauges in cylinders of Teflon or PBX 9501 that were in contact with the donor. A third experiment measured the thermal distribution in a Teflon system using the same metal fixture and the same heating rates used in the explosive donor experiments.

The first experiment (TEXT IV) is shown in Figure 1. The PBX 9501 cylindrical disc is confined by 304 Stainless Steel case. The HE disc and case were designed so that the explosive would come into contact with all surfaces when the explosive was near $150^{\circ} \mathrm{C}$. Some uncertainty still existed on when the HE came into contact, because the HE was not uniformly heated as it was assumed by thermal expansion calculations.

The stainless steel case consisted of a tube $90 \mathrm{~mm}$ long with $34.5 \mathrm{~mm}$ thick walls whose inside diameter was $9.0 \mathrm{~cm}$. The donor charge was placed inside the tube. It was a PBX 9501 explosive weighing $295 \mathrm{~g}$ whose dimensions were $90 \mathrm{~mm}$ in diameter and $25 \mathrm{~mm}$ thick. Two $3 \mathrm{~mm}$ thick 6061-T6 aluminum plates were placed between the steel plates and the explosive charge to distribute the heat faster and more uniformly than would the steel plate. The aluminum plate also served as a gasket for a pressure seal since both steel interfaces had knife edges machined in them. The whole case with the donor charge in it was held together with several "grade A" hardened steel bolts tightened to $95 \mathrm{~N}-\mathrm{m}$ (70 ft-lbs). 
The flat Nichrome spiral ribbon heater shown in Fig. 2 was placed between the steel cover plate and the aluminum plate. The two thermocouples are to monitor the temperature and to control the heating rate of the heater. No thermocouples were placed internal to the steel encased PBX 9501 to allow for a simple pressure seal design for the steel fixture.

\section{Thermal Explosion Experiment Teflon TEXT-4}

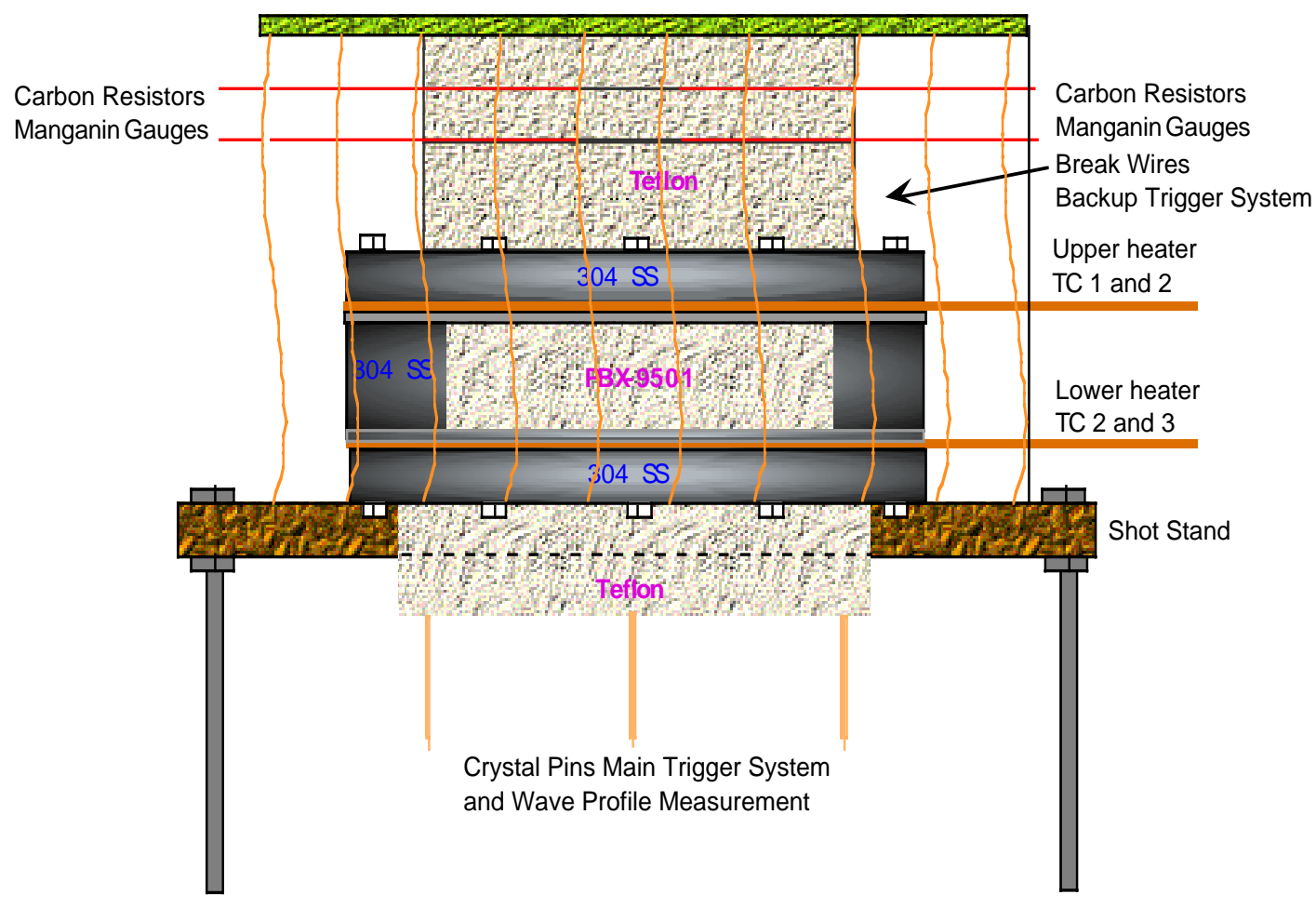

Figure 1. Schematic of TEXT IV gauged thermal explosion experiment

The triggering of the power supplies and the digitizers is a critical feature of this experiment. For the primary triggering system and to measure the wave arrival times at the bottom steel plate surface, a series of thirteen PZT pins were placed against that surface in a cross pattern with one pin at the center and each pin being $15 \mathrm{~mm}$ center to center distance apart. The thirteen PZT pins were all summed so that any one of them would trigger the digitizers and the power supply for the manganin gauges. A back-up break wire trigger system was also used in case the primary system failed. This system provided a trigger pulse from a circuit if any of the wires broke. These break wires were also summed so the first one to break would trigger the digitizers and power supplies. Recall that the modern TDS digitizers continuously cycle records until a trigger signal stops it. The digitizer then captures events ahead and behind the trigger signal at amounts determined by the settings. This gives some flexibility in performing these cook-off experiments that have uncertainty in when and where the trigger signal will originate.

The manganin and carbon resistor gauges were embedded in the acceptor Teflon cylinder at 19 and $25 \mathrm{~mm}$ from the hot flat steel HE container surface. A schematic of the gauge placement in the Teflon discs is shown in Fig. 2. The carbon resistor gauges were placed in machined grooves of the Teflon disc surfaces while the manganin gauges were packaged between two $0.13 \mathrm{~mm}$ thick Teflon insulating sheets. 
Carbon resistor gauges have been successfully used in two-dimensional shock wave experiments where time resolution was sacrificed for survival of the gauge. ${ }^{1-4}$ The constant current power supply for the carbon resistor gauges were always on passing about $18 \mathrm{~mA}$ through the $470 \mathrm{ohm}$ resistors. The constant current pulse power supply for the manganin gauges was the Dynasen CK2-50/0.050-300, driving the gauge with a constant current of 50A.

Manganin gauges have been used successfully in numerous one-dimensional strain experiments ${ }^{5}$ It has also been shown to be temperature insensitive ${ }^{6-7}$. Numerous papers in the literature discuss the calibration of this gauge, but only few ${ }^{8-12}$ are selected here for reference.
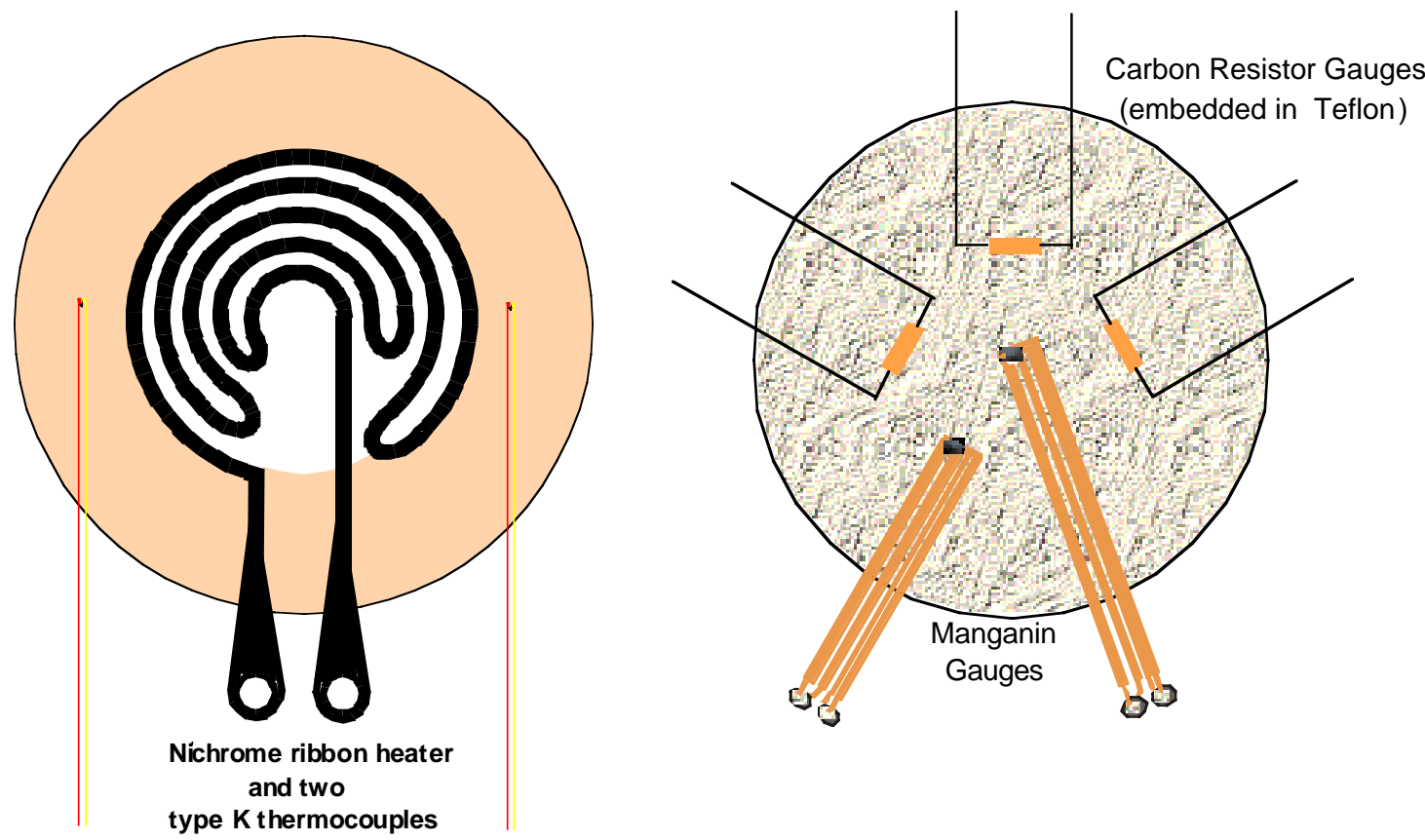
type $\mathrm{K}$ thermocouples

Figure 2. Heater, thermocouple and gauge arrangements

For TEXT IV the heat was delivered to the donor at a rate of $5^{\circ} \mathrm{C}$ a minute until the thermocouples recorded $170^{\circ} \mathrm{C}$. The controllers then allowed the heaters to overshoot to $185^{\circ} \mathrm{C}$ for 7 minutes and then brought the temperature back to $170^{\circ} \mathrm{C}$ after 28 more minutes. The heating rate at the steel cover plate then went to $1^{\circ} \mathrm{C} / \mathrm{min}$ until the temperature at the steel plate reached $210^{\circ} \mathrm{C}$ and the PBX 9501 inside the case went off.

Experiment TEXT V was a thermal simulation experiment with the Teflon discs inside the steel case replacing the PBX 9501 discs. Thermocouples were at a number of interfaces in this mock donor system. The same heating procedure was applied to this inert donor system. The thermal traces are not reported here but can be used to calibrate a thermal code, which can then provide the time and spatial history of the heated PBX 9501 donor up to where reaction begins in the HE donor. Recall that no thermocouples were used inside the donor explosives for these experiments.

Experiment TEXT VI is shown in Fig. 3 and was similar to the TEXT IV except in this case the acceptor cylinder was PBX 9501 and more gauges were used. Both manganin and carbon resistor gauges were placed at different depths in the PBX 9501 cylinder acceptor. 
A $10 \mathrm{~mm}$ thick Teflon disc is placed between the steel top plate of the confined donor system and the acceptor to provide thermal insulation for the acceptor charge. This insures that the acceptor does not overheat to cause the cook-off. A second benefit is to keep the temperature down on the carbon resistor gauges since they are temperature sensitive and no calibration has been done for these gauges at temperature.

Thermal Explosion Experiment PBX-9501 TEXT-6

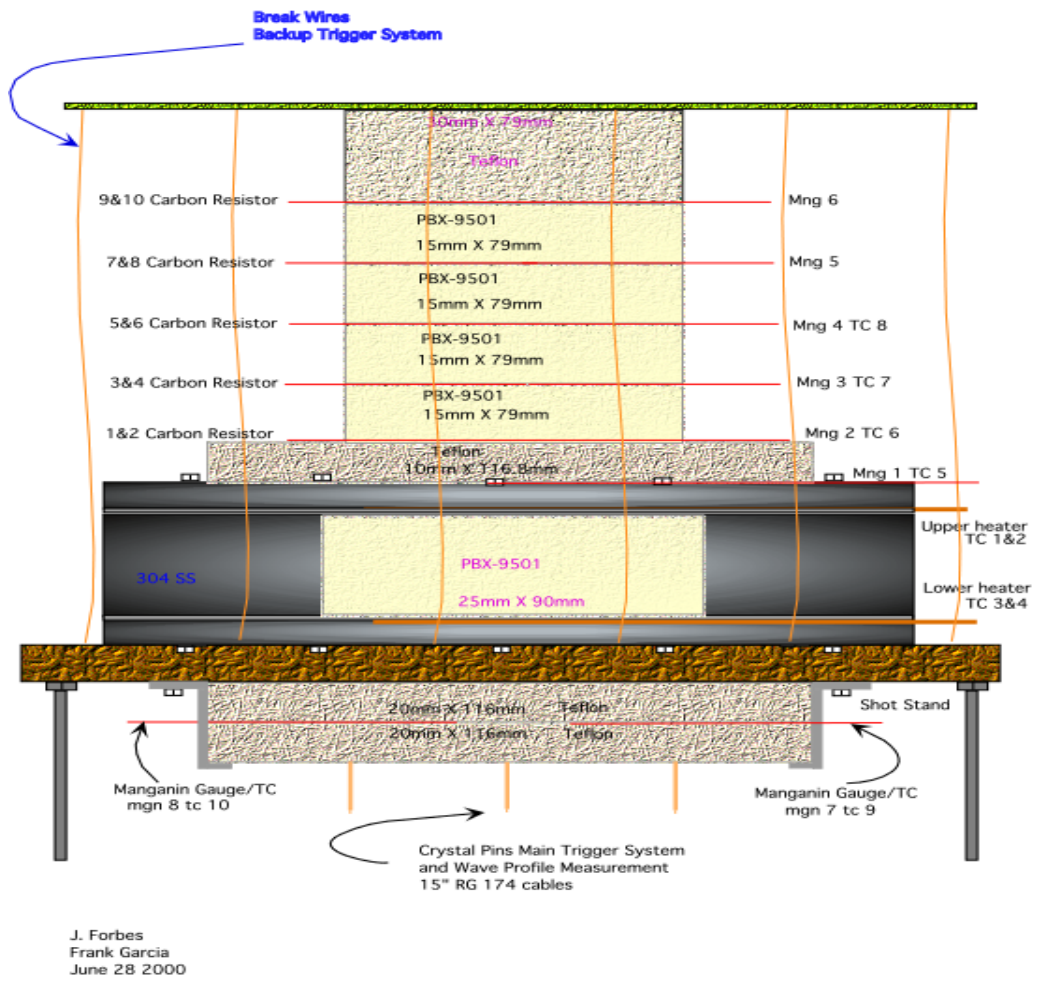

Figure 3. Schematic for TEXT VI thermal explosion experiment

The donor charge system and the PZT pin arrangement on TEXT VI is basically the same as described for TEXT IV experiment. The one difference on the PZT pin set-up is to add thermocouples and manganin gauges between the two $20 \mathrm{~mm}$ thick Teflon discs holding the PZT pins in place. The two triggering systems of PZT pins and break wires were the same as described for TEXT IV.

\section{RESULTS}

\section{EXPERIMENT TEXT IV}

A high-pressure ramp wave was measured in TEXT IV by carbon resistor gauges with peak pressure near $4.3 \mathrm{~kb}$ at $19 \mathrm{~mm}$ distance and $3.5 \mathrm{~kb}$ at $25 \mathrm{~mm}$ distance in the Teflon. These gauge records are shown in Fig. 4. The carbon resistor gauges appear to have broken just after reaching peak pressures. The manganin gauge records are not shown here because they were set to record only short times. These short recording times for manganin were chosen for this first experiment in case a constant volume thermal explosion occurred in the donor which would have resulted in high pressures of approximately $1 / 2$ the CJ pressure of PBX 9501. 

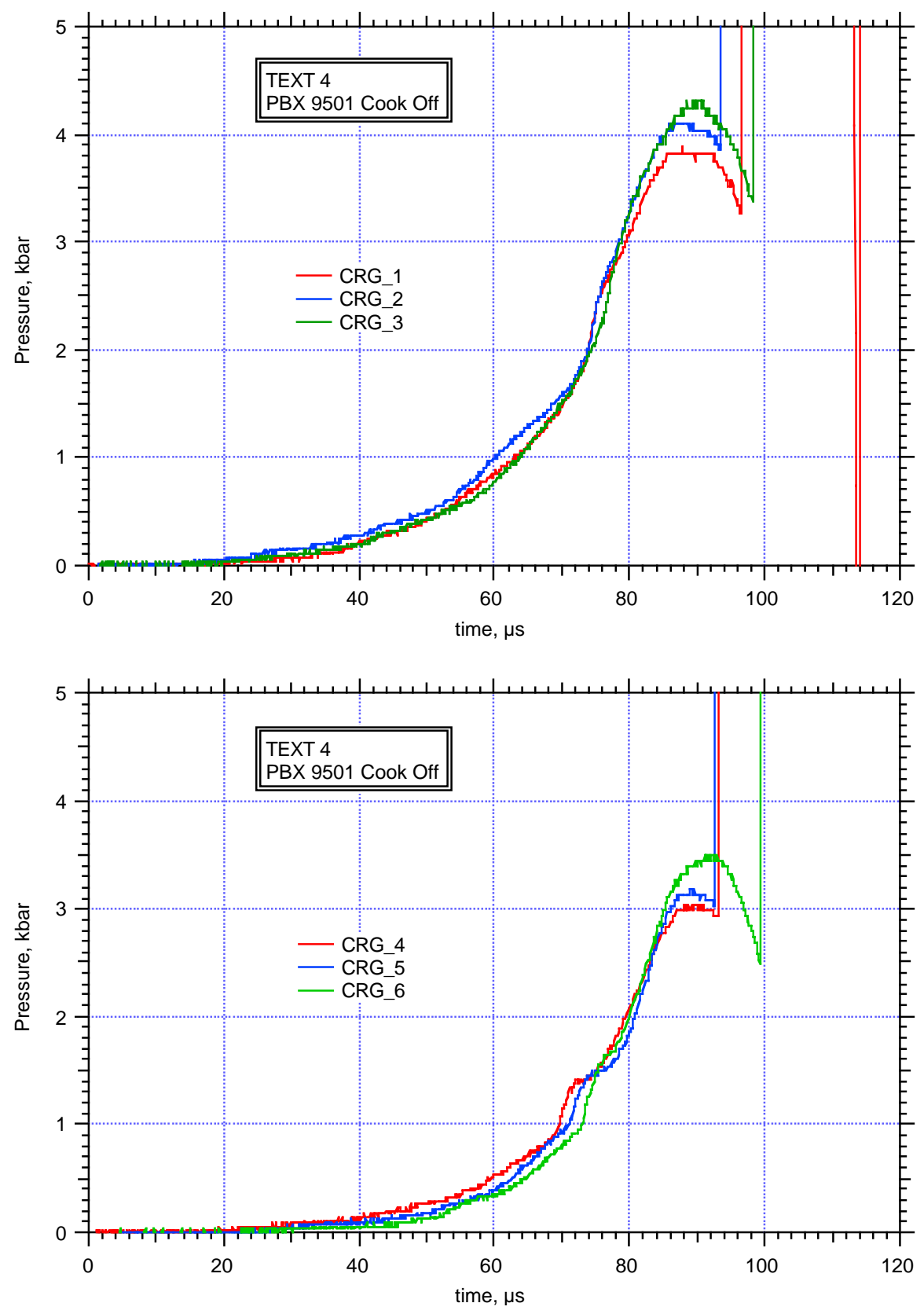

Figure 4. Carbon resistor gauge records for TEXT IV experiment.

The wave arrival times at the PZT pins are shown in Fig. 5. The analysis of pin arrival times with their location also indicates that the reaction started slightly off center as shown in Fig. 6 . The phase velocity across the steel surface where the PZT pins were located gave a velocity of about $1 \mathrm{~mm} / \mu \mathrm{s}$. This slow phase velocity shows that a burning reaction occurred and not a true constant volume thermal explosion. 


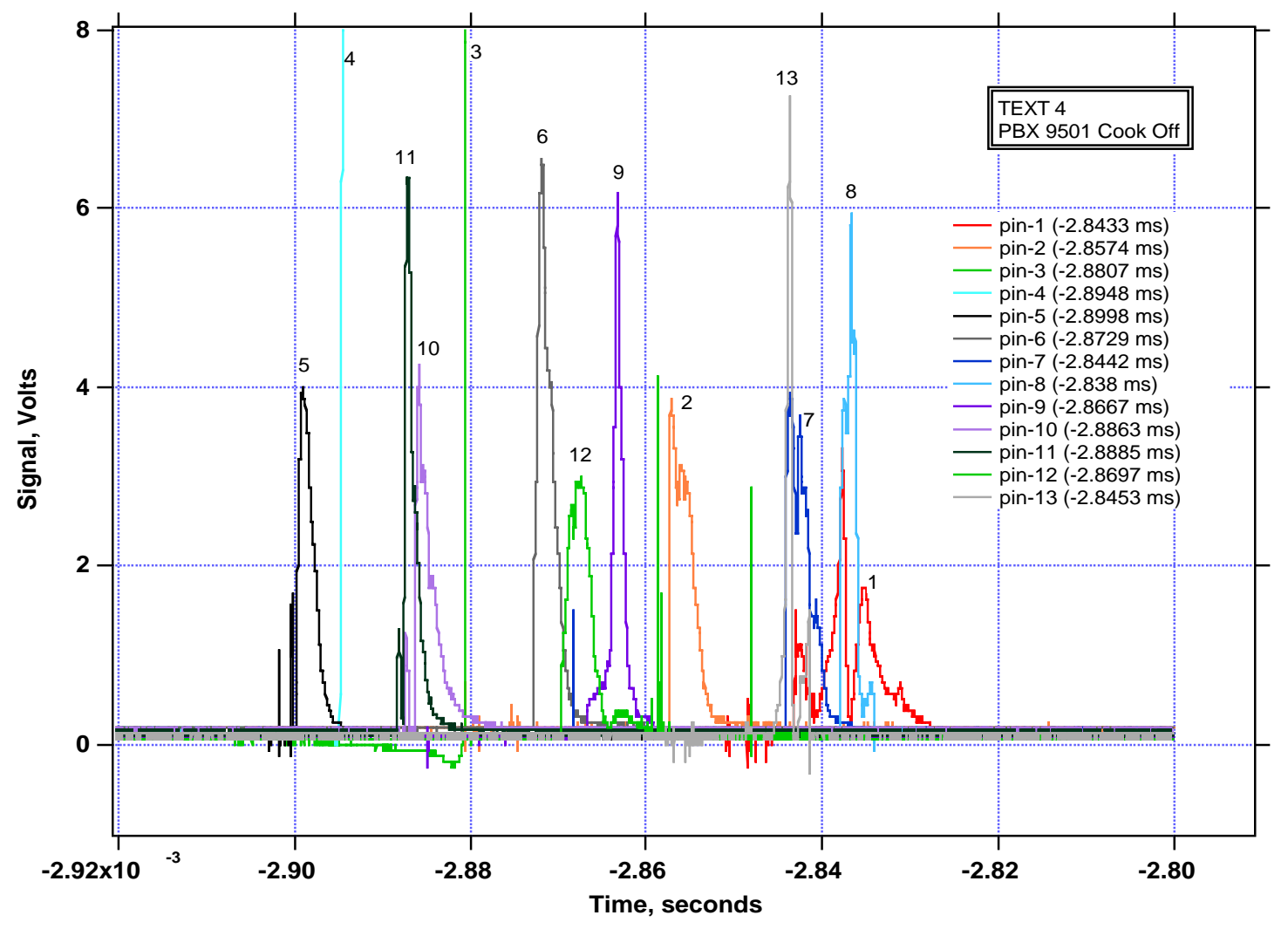

Figure 5. PZT pin records for TEXT IV

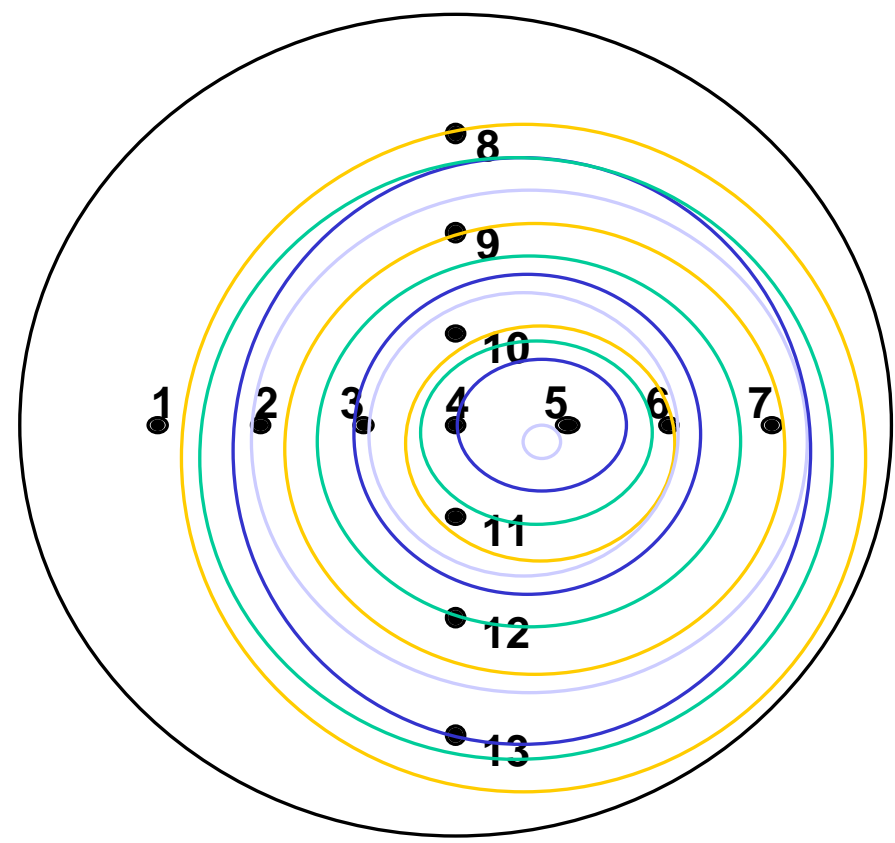

Figure 6. PZT pin contours for TEXT IV derived from the arrival time records 


\section{EXPERIMENT TEXT VI}

Figure 7 gives the temperature time profiles for the five thermocouples that behaved well for TEXT VI. Their locations are given in Fig. 3. These show that rapid explosion occurred when the thermocouples at the metal surface of the donor system reached $209^{\circ} \mathrm{C}$. The initial heating rate was $5^{\circ} \mathrm{C}$ per minute up to $170^{\circ} \mathrm{C}$ at the metal surface of the donor. Then the temperature at this surface was held at $170^{\circ} \mathrm{C}$ for 35 minutes to allow for the donor to be somewhat uniform in temperature. The temperatures in the acceptor did increase but at much lower rates. These temperatures are high enough that the carbon resistor gauge calibration will need to be done for this range of temperatures to improve the accuracy of these measurements.

The carbon resistor pressure gauge results (without temperature corrections) in Fig. 8 show that a ramp wave with peak pressure of $12 \mathrm{~kb}$ exists at the first gauge level in the acceptor. Some variation in gauge pressure exists for gauges on the same plane, which is likely due to the ramp wave not being symmetric as it propagates into the acceptor. Variation between gauges is smaller than this observed difference of $2 \mathrm{~kb}$ at the first gauge station. The ramp pressure wave decays very rapidly as it moves up the acceptor charge and the rise time of the ramp lengthens. This decay is faster than observed in the Teflon acceptor of TEXT IV consistent with PBX 9501 being a stiffer material with faster release wave speeds. It is clear that for TEXT VI the wave did not build into a detonation, which would be a more severe safety issue. The decay of the ramp wave peak pressure is given in Figure 9. The peak pressure decay is fitted accurately to an exponential function.

TEXT-VI Temperature Profile

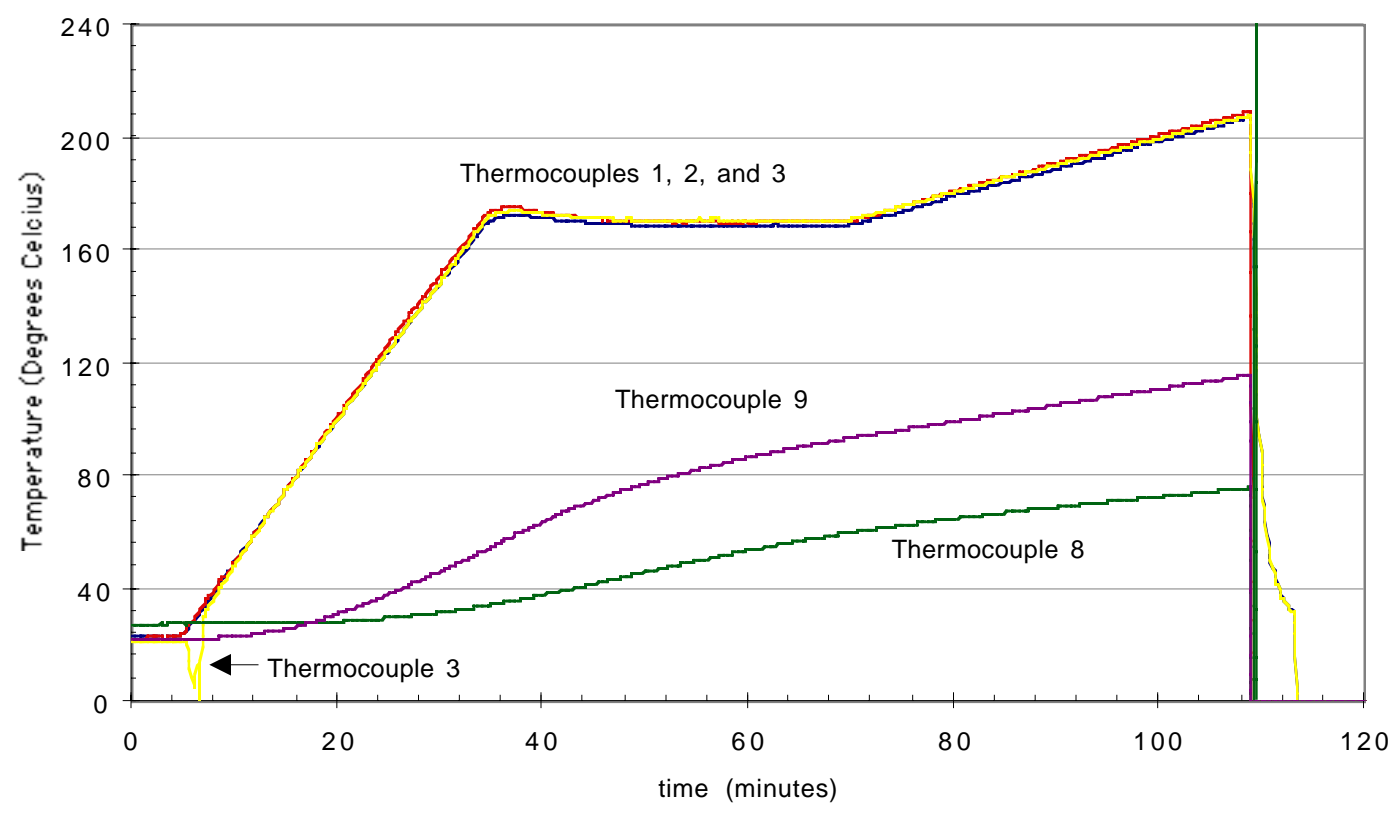

Figure 7. Temperature profiles of various thermocouples at various locations in the TEXT VI target 


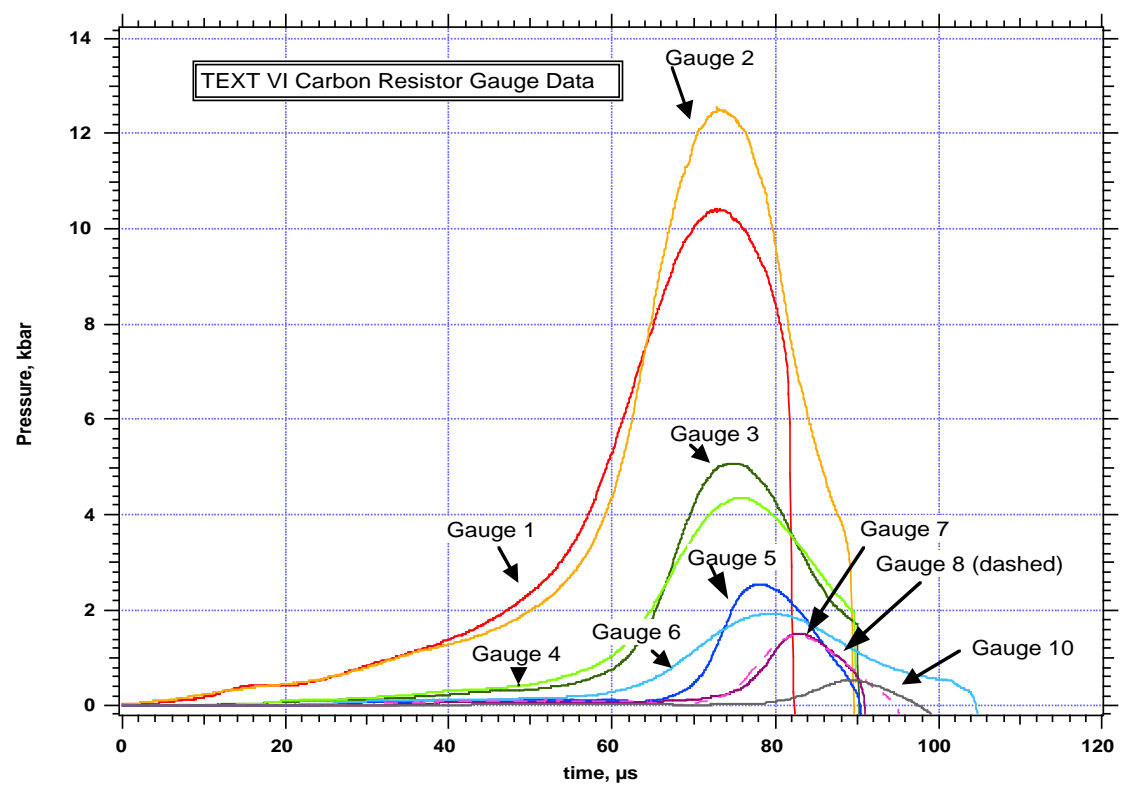

Figure 8. Carbon resistor pressure gauge results for TEXT VI

TEXT VI Carbon Resistor Gauge Maximum Pressure Profile

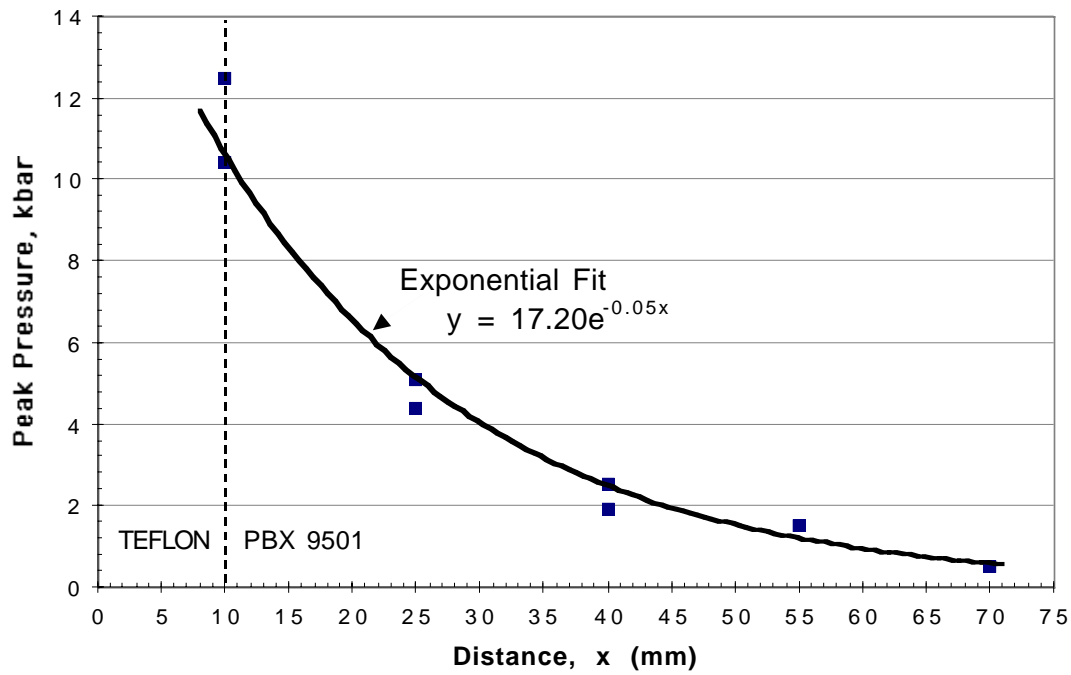

Figure 9. Peak pressures of the carbon resistor gauges as a function of Lagrange distance 


\section{SUMMARY AND CONCLUSIONS}

A multi-dimensional ramp pressure wave is transmitted to the acceptor materials (Teflon or PBX 9501) from an explosive deflagration cook-off of a confined PBX 9501 donor system with a peak pressure of around $12 \mathrm{~kb}$. This ramp wave's peak pressure decays rapidly while the rise time of the ramp decreases. These pressures are substantial and will scatter burning materials around significantly but for these experimental conditions build-up to detonation in the acceptor does not occur.

Future work on this area will include additional experiments with different heating rates and confinement. In addition, some future experiments will measure the velocity of the steel cover plate as a function of travel to see if a sympathetic detonation in a neighboring explosive device with a reasonable stand off is possible. Note that a ramp wave such as seen in these experiments will accelerate the cover plate of the donor system in a manner similar to the acceleration of a projectile by a powder gun. For future experiments, where violent reaction may be expected to occur, manganin gauges would be a natural choice. However, they are known to be sensitive to lateral strain. This makes this gauge mainly useful for one-dimensional strain experiments. For two-dimensional dynamic strain experiments, J. Charest ${ }^{13}$ has shown that the gauge analysis can correct the signals for small strains. This requires the use of a strain gauge in the experiment at the same location (or very close) to the manganin gauge element. Strain gauges will be added to the manganin gauge package for future experiments to get pressure corrected for lateral strain. Temporal resolution of this gauge package with strain gauges will be less than $100 \mu \mathrm{s}$. A thermal and hydrodynamic coupled code DYNA 2D and ALE 3D will be used to model the results of these and future experiments.

\section{ACKNOWLEDGEMENTS}

Jerry Dow obtained the funding for us to do this work. Pat McMaster and Gary Steinhour assisted on the experiments. Douglas Tasker (LANL) and William Wilson (Eglin AFB) are acknowledged for sharing their information on the use of carbon resistor gauge. Douglas Tasker designed the constant current power supply for the carbon resistor gauge.

* This work was performed under the auspices of the U. S. Department of Energy by the University of California, Lawrence Livermore National Laboratory under Contract No. W-7405Eng-48.

\section{REFERENCES}

1. Ginsberg, Michael J., and Asay, Blaine W., "Commercial Carbon Composition Resistors as Dynamic Stress Gauges in Difficult Environments," Rev. Sci. Instrum. 62 (9): 2218-2227 (1991).

2. Wilson, W. H., "Experimental Study of Reaction and Stress Growth in Projectile-Impacted Explosives," Shock Compression of Condensed Matter-1991, eds. Schmidt, Dick, Forbes, and Tasker, Elsevier Science Publishers, pp. 671-674 (1992).

3. Austing, J. L., Tulis, A. J., Hrdina, D. J., and Baker, D. E., "Carbon Resistor Gauges for Measuring Shock and Detonation Pressures I. Principles of Functioning and Calibration, Propellants, Explosives, Pyrotechnics 16, pp. 205-215 (1991).

4. Forbes, J. W., Tarver, C. M., Chidester, S. K., Garcia, F., Greenwood, D. W., Garza, R, "Measurement of Low Level Explosives Reaction in the Two-dimensional Steven Impact Test ${ }^{\star}$ $19^{\text {th }}$ Propulsion Systems Hazards Subcommittee (PSHS) Meeting, Monterey, CA. 13-17 November (2000)

5. Urtiew, P. A., Forbes, J. W., "Experimental Study of Low Amplitude, Long-Duration Mechanical Loading of Reactive Materials", $19^{\text {th }}$ Propulsion Systems Hazards Subcommittee (PSHS) Meeting, Monterey, CA. 13-17 November (2000).

6. Bernstein, D. and Keough, D.D., "Piezoresistivity of Manganin," J. Appl. Phys, $\underline{35}$, No. 5, pp. 1471-1474 (1964). 
7. Urtiew, P.A., Forbes, J.W., Tarver, C.M. and Garcia, F., "Calibration of Manganin Gauges at $250^{\circ} \mathrm{C}$ ", Shock Compression in Condensed Matter, Furnish, M.D.,Chhabildas, L.C. and Hixson, R.S. eds., AIP Press, New York, pp. 1019 - 1022 (1999).

8. Gupta, Y.M., " Analysis of Manganin and Ytterbium Gauge under Shock Loading", J. Appl. Phys., 54 (11), pp. 6094-6098, Nov. (1983).

9. Gupta, S. C., and Gupta, Y. M., "Experimental Measurements and Analysis of the Loading and Unloading Response of Longitudinal and Lateral Gauges Shocked to 90 kbar", J. Appl. Phys., $\underline{62}$ (7), p. 2603, Oct. (1987).

10. Vantine, H.C., Erickson, L.M. and Janzen, J., "Hysteresis-Corrected Calibration of Manganin under Shock Loading", J. Appl. Phys., 51 (4), April (1980).

11. Vantine H., Chan J., Erickson L. M., Janzen J., Lee R. and Weingart R. C., "Precision Stress Measurements in Severe Shock-Wave Environments with Low Impedance Manganin Gauges,"

Rev. Sci. Instr., 51. pp. 116-122 (1980).

12. Gupta, Y. M., "Analysis of Manganin and Ytterbium Gauge Data under Shock Loading," J. App. Phys., $\underline{54}$ (11): 6094-6098 (1983).

13. Charest, J. A., "Development of a Strain Compensated Shock Pressure Gauge, Dynasen Inc. Goleta, CA., TR-001 (1976). 